\title{
The Influence of Regular Hemodialysis on the Highly Sensitive Troponin-I Level in Children without Any Symptoms
}

\author{
Hekmat Mohamed1', Maha Youssef ${ }^{1}$, Manal Abdel-Salam ${ }^{1}$, Shayma A. Mohammed ${ }^{2}$ \\ ${ }^{1}$ Department of Pediatrics, Faculty of Medicine (for Girls), Al-Azhar University, Cairo, Egypt \\ ${ }^{2}$ Department of Clinical Pathology, Faculty of Medicine (for Girls), Al-Azhar University, Cairo, Egypt \\ Email: *manal24969@gmail.com
}

How to cite this paper: Mohamed, H., Youssef, M., Abdel-Salam, M. and Mohammed, S.A. (2021) The Influence of Regular Hemodialysis on the Highly Sensitive Troponin-I Level in Children without Any Symptoms. Open Journal of Nephrology, 11, 183-198.

https://doi.org/10.4236/ojneph.2021.112015

Received: April 2, 2021

Accepted: May 10, 2021

Published: May 13, 2021

Copyright $\odot 2021$ by author(s) and Scientific Research Publishing Inc. This work is licensed under the Creative Commons Attribution International License (CC BY 4.0).

http://creativecommons.org/licenses/by/4.0/

\begin{abstract}
Backgrounds: Cardiovascular diseases are still the prominent cause of death in cases of end-stage renal disease, cardiac troponin I (cTnI) can be used for detecting cardiac involvement in asymptomatic cases of end-stage renal disease on hemodialysis. Aim: Determine the direct cardiac consequence of dialysis treatments in children on hemodialysis by measuring high-sensitive troponin-I as a marker of myocardial injury. Subjects and Methods: This case-control study included thirty children with end-stage renal disease on regular hemodialysis; the study group was selected from the nephrology hemodialysis unit of Al-Zahraa Hospital, Al-Azhar University. Another group of thirty healthy children matches age and sex with the patient's group as a control. Highly Sensitive cTnI (hsTnI) was measured pre and post hemodialysis with a sensitive assay; moreover, ECG, lipid profile including cholesterol, triglyceride, low and high-density lipoprotein (HDL) in the same line with routine investigations for those patients, we used bioimpedance for dry weight assessment in the hemodialysis (HD) group. Results: Children on (HD) have a significantly higher (hsTnI) pre-dialysis $(0.250 \pm 0.069 \mathrm{ng} / \mathrm{ml})$ compared to post-dialysis $(0.187 \pm 0.004 \mathrm{ng} / \mathrm{ml})$ with $(\mathrm{p}, 0.001)$. With no significant difference between post $\mathrm{HD}(0.187 \pm 0.004 \mathrm{ng} / \mathrm{ml})$ and the control group $(0.189$ $\pm 0.005)$ with (p, 0.090). $c T n I$ is detected in $(73.3 \%)$ of children pre-dialysis above the cut-off value compared to (3.31\%) had a high-level post-dialysis. cTnI is positively correlated with systolic, diastolic blood pressure and heart rate with ( $\mathrm{r}$. 0.333, p, 0.001: r. 0.343, p, 0.001: r. 0.276, p, 0.033) respectively and (hsTnI) is negatively correlated with $\mathrm{Hb}$ and $\mathrm{HDL}$ (r. -0.333, p, 0.009: r. 0.324, p, 0.011). Meanwhile (hsTnI) is positively correlated with serum urea, creatinine, ph, PTH, serum ferritin and positively correlated with QT interval and QTC. Conclusion: $\mathrm{cTnI}$ levels rise significantly before hemodialysis, so those pa-
\end{abstract}


tients are exposed to silent myocardial injury pre $\mathrm{HD}$, and fortunately, it is not persistent after hemodialysis except for a few of them had a high level. We strongly advised not to delay dialysis appointments; the nephrology team should aggressively treat those patients to prevent further myocardial damage.

\section{Keywords}

Highly Sensitive Troponin-I, Children, Hemodialysis

\section{Introduction}

Cardiovascular disease (CVD) is the most common cause of death in pediatric CKD patients [1] [2] [3]. For children on regular hemodialysis, the mortality associated with cardiac disease is one thousand times higher than in normal children [4]. CVD was the leading cause of mortality in patients undergoing dialysis, affecting 33\% of cases in a cohort of US children, followed from 1995 to 2010 [5].

Children and uremia patients with uremia have a similar constellation of ischemia-predisposing factors to adults, including vascular calcification, increased intima-media thickness and pulse wave velocity, early atherosclerosis, and endothelial dysfunction [6] [7], but without significant atheromatous coronary artery disease.

The incidence of HD-induced hemodynamic disturbance is comparable to adults, with a $20 \%$ to $30 \%$ incidence of intradialytic hypotension associated with a relative blood volume reduction of $20 \%$ to $25 \%$ [8].

High-sensitive troponin I (hsTnI) and high-sensitive troponin $\mathrm{T}$ (hsTnT) are markers of cardiac damage. Cardiomyocyte necrosis increases its blood levels. It is known that dialysis is cardiotoxic, resulting in a lack of contractility of certain myocardial segments. This mechanism is primarily due to hypoperfusion of the myocardium during dialysis.

The dialysis itself increases cardiovascular risk in patients by many different mechanisms. It has been proven that the incidence of heart failure is much more frequent in patients on hemodialysis than in healthy populations [9]. Studies regarding the effect of HD on TnI levels, measured by conventional assays, are contradictory [10] [11].

Few studies were using hsTnI assay in HD patients. The percentage of asymptomatic HD patients who had pre-dialysis hsTnI levels higher than the reference cutoff point was $5 \%-51 \%$. The studies that used the newer hsTnI assay still provided limited data [12] [13].

The most common conditions that lead to elevation of the troponin level in the blood are myocardial infarction, toxic damage to the heart, and pulmonary embolism [14].

Children are the best model of patients with uremia for defining the risk for 
demand myocardial ischemia because they lack "classical" epicardial plaque-based coronary artery disease.

\section{Subjects and Methods}

This case-control study was carried on 30 children with CKD on regular HD and 30 children as a control group matched age and sex with patients group. They were selected from the outpatient clinic and HD unit of the Al-Azhar University Hospital. The patient group was on regular HD for longer than three months at the time of the study [15], for four h/setting, three times weekly, using low-flux polysulfone dialyzer and 4008 Fresenius machine. The most common cause of CKD in the patient's group was acquired 11 (35.0\%), congenital causes 8 (26.7\%) and hereditary causes 4 (13.3\%), and unknown causes in 7 (23.3\%). Patients with congenital or acquired heart disease, heart failure, or any other chronic illness excluded from the study. Informed consent was obtained from the parents of the participating children in adherence with the guidelines of the Ethical Committee of Al-Zahra Hospital, Al-Azhar University, Cairo, Egypt.

Sample collection and laboratory investigations of children pre-HD: Under a complete aseptic condition, a volume of $10 \mathrm{ml}$ of venous blood was withdrawn from each subject after fasting for $12 \mathrm{hrs}$. We divided the blood sample into two aliquots; the first aliquot of $2 \mathrm{ml}$ of blood was transferred into an EDTA tube for measuring complete blood count (Sysmex XK-21, Japan). 2nd aliquot of $8 \mathrm{ml}$ was transferred into two serum gel separator tubes and centrifuged for separation of serum. We divided the serum into four parts. The 1st part of the serum was used for the measurement of urea, creatinine, and lipid profile (total cholesterol (CHO), triglyceride (TG), low-density lipoprotein (LDL) and high-density lipoprotein $(\mathrm{HDL})$, total blood $\mathrm{Ca}$, and phosphorus $(\mathrm{Ph}+)$ using chemistry auto-analyzer device (Cobas Integra 400 plus, Roche diagnostics, Germany). The 2nd part was used for the measurement of electrolytes, including sodium $(\mathrm{Na}+)$ and potassium $(\mathrm{K}+$ ), by electrolyte analyzer (AVL, 9180 Roche diagnostics, Germany). We used the 3rd portion to measure serum ferritin and PTH by immunoassay using direct chemiluminescent technology (Cobas e411, Roche diagnostics, Germany by chemiluminescence technique). The last portion was stored at $-20^{\circ}$ to measure cardiac-specific Troponin I (cTn-I), which was done by enzyme-linked immunosorbent assay (ELISA).

Another sample, about $2 \mathrm{ml}$ blood, was withdrawn after dialysis and transferred to serum gel separator tube and centrifuged again for measurement of (hsTnI) post-dialysis for comparison with its value before dialysis, which (ELISA also measured).

ELISA assay for measurement of (cTn-I): ELISA using kits supplied from Beta trade, Diagnostics, USA, with Lot NO319081302 Rev. K according to Manufacturer instructions with a lower detection limit of $0.010 \mathrm{ng} / \mathrm{ml}$ and sensitivity of $0.04 \mathrm{ng} / \mathrm{ml}$. Elisa system used was varioscan lux, thermo-scientific; USA (well washer).

Resting ECG: Resting ECG (monitors Ltd., Rostov-on-Don, Russia) for the 
patient's group after 5 minutes of complete flat rest pre-hemodialysis, 12 standard leads for the hemodialysis group.

Statistical analysis: Data were collected, revised, coded, and entered into the Statistical Package for Social Science (IBM SPSS) version 23. Spearman correlation coefficients to assess the correlation between two studied parameters in the same group. Receiver Operating Characteristic (ROC) curve was used to assess the best cutoff point with sensitivity and specificity. Interpretation of probability values was as follows: $\mathrm{p}>0.05$ : non-significant, $\mathrm{p}<0.05$ : significant.

\section{Results}

Table 1 shows a significant decrease in weight and height in hemodialysis children than healthy controls; meanwhile, there is a significant increase in the systolic, diastolic blood pressure, and heart rate compared to healthy controls.

Table 2 shows a significant decrease in $\mathrm{Hb}$, platelet counts, and HDL serum level; meanwhile, there is a significant increase in serum urea, creatinine, phosphate, and triglyceride in hemodialysis children than in their controls.

Table 3 shows a significant increase in serum level of hsTnI in children pre-HD than healthy controls, but it significantly reduced in post-dialysis reached to be of no significant difference compared to healthy controls.

Table 4 shows ECG abnormalities in the patient's group before the hemodialysis; despite the study, patients with no cardiac symptoms, prolonged QT, and QTC were detected in 16 (53.3\%) and 10 (33.3\%), respectively. Meanwhile, inverted $\mathrm{T}$ and $\mathrm{LV}$ enlargement were detected in 7 (23.3\%) and 6 (20.0\%), respectively.

Table 1. Comparison between control group and patients group regarding age, sex, blood pressure, and anthropometric measurements.

\begin{tabular}{|c|c|c|c|c|c|}
\hline \multirow[b]{2}{*}{ Variables } & \multirow[t]{2}{*}{ Groups } & Control group & Patients group & \multirow{2}{*}{ t. test } & \multirow{2}{*}{ p-value } \\
\hline & & No. $=30$ & No. $=30$ & & \\
\hline Age (years) & Mean \pm SD & $10.77 \pm 2.87$ & $12.00 \pm 3.46$ & 1.501 & 0.139 \\
\hline \multirow[b]{2}{*}{ Sex } & Female & $17(56.7 \%)$ & $12(40.0 \%)$ & \multirow[b]{2}{*}{$1.669^{*}$} & \multirow[b]{2}{*}{0.196} \\
\hline & Male & $13(43.3 \%)$ & $18(60.0 \%)$ & & \\
\hline \multicolumn{2}{|c|}{ Weight z-score, median (IQR) } & $0.07(-0.50-0.90)$ & $-0.60(-0.80-0.00)$ & $2.980 \neq$ & 0.003 \\
\hline \multicolumn{2}{|c|}{ Height z-score, median (IQR) } & $0.07(-0.23-1.10)$ & $-0.50(-0.96-0.05)$ & $3.029 \neq$ & 0.002 \\
\hline \multicolumn{2}{|c|}{ BMI z-score, median (IQR) } & $-0.16(-0.50-0.56)$ & $-0.38(-0.72-0.22)$ & $1.220 \neq$ & 0.223 \\
\hline \multicolumn{2}{|c|}{ SBP (mmHg) } & $98.33 \pm 7.23$ & $128.67 \pm 29.68$ & $5.4390 \bullet$ & 0.000 \\
\hline \multicolumn{2}{|c|}{$\mathrm{DBP}(\mathrm{mmHg})$} & $61.33 \pm 3.20$ & $83.67 \pm 25.26$ & $4.8050 \bullet$ & 0.000 \\
\hline \multicolumn{2}{|c|}{$\mathrm{HR}$ (beat/min) } & $73.80 \pm 14.54$ & $86.10 \pm 12.71$ & $3.4880 \bullet$ & 0.001 \\
\hline $\begin{array}{c}\text { Duration of } \\
\text { haemodialysis } \\
\text { (years) }\end{array}$ & $\begin{array}{c}\text { Median } \\
\text { (IQR) }\end{array}$ & - & $3.5(2-4)$ & - & - \\
\hline
\end{tabular}

\#: Mann Whitney test. 
Table 2. Comparison between control group and patients group regarding laboratory data.

\begin{tabular}{|c|c|c|c|c|}
\hline \multirow{2}{*}{ Variables } & $\begin{array}{l}\text { Control group } \\
\text { No. } 30\end{array}$ & $\begin{array}{l}\text { Patients group } \\
\text { No. } 30\end{array}$ & \multirow{2}{*}{$\mathrm{t}$.value } & \multirow{2}{*}{ p-value } \\
\hline & $\begin{array}{c}\text { Mean } \pm \text { SD/ } \\
\text { Median (IQR) }\end{array}$ & $\begin{array}{c}\text { Mean } \pm \text { SD } / \\
\text { Median (IQR) }\end{array}$ & & \\
\hline $\operatorname{TLC}\left(\times 10^{3} / \mu \mathrm{l}\right)$ & $6.47 \pm 0.94$ & $6.59 \pm 1.81$ & $-0.331 \bullet$ & 0.742 \\
\hline $\mathrm{RBCs}\left(\times 10^{6} / \mu \mathrm{l}\right)$ & $5.07 \pm 1.25$ & $4.32 \pm 2.38$ & $1.531 \bullet$ & 0.131 \\
\hline $\mathrm{Hb}(\mathrm{g} / \mathrm{dl})$ & $12.27 \pm 0.55$ & $9.48 \pm 1.67$ & $8.700 \bullet$ & 0.001 \\
\hline Hct (\%) & $37.52 \pm 4.23$ & $31.79 \pm 12.17$ & $2.437 \bullet$ & 0.018 \\
\hline $\operatorname{PLT}\left(\times 10^{3} / \mu \mathrm{l}\right)$ & $294.70 \pm 52.57$ & $190.03 \pm 55.32$ & $7.512 \bullet$ & 0.001 \\
\hline MCV (FL) & $88.33 \pm 5.15$ & $86.05 \pm 6.30$ & $1.534 \bullet$ & 0.13 \\
\hline Urea (mg/dl) & $21.20 \pm 7.19$ & $139.67 \pm 33.84$ & $-18.757 \bullet$ & 0.00 \\
\hline Creatinine (mg/dl) & $0.65(0.5-0.8)$ & $7.15(6.5-8.5)$ & $-6.631 \neq$ & $0 / 00$ \\
\hline $\mathrm{Na}(\mathrm{mEq} / \mathrm{L})$ & $136.87 \pm 1.74$ & $134.67 \pm 25.17$ & $0.478 \bullet$ & 0.635 \\
\hline $\mathrm{K}(\mathrm{mEq} / \mathrm{L})$ & $4.10 \pm 0.36$ & $4.96 \pm 1.07$ & -4.170 • & 0.001 \\
\hline $\mathrm{Ca}(\mathrm{mg} / \mathrm{dl})$ & $9.16 \pm 0.43$ & $9.26 \pm 1.40$ & $-0.374 \bullet$ & 0.71 \\
\hline $\mathrm{Ph}(\mathrm{mg} / \mathrm{dl})$ & $3.49 \pm 0.44$ & $5.63 \pm 1.44$ & $7.773 \bullet$ & 0.001 \\
\hline PTH (Pg/ml) & $31.5(21-41)$ & $209(51-543.2)$ & $-4.843 \neq$ & 0.001 \\
\hline Ferritin (ng/ml) & $70.5(37-111)$ & $720.5(271-1437)$ & $-5.486 \neq$ & 0.00 \\
\hline $\begin{array}{c}\text { S. cholesterol } \\
(\mathrm{mg} / \mathrm{dl})\end{array}$ & $153.57 \pm 27.18$ & $160.13 \pm 59.94$ & -0.547 & 0.587 \\
\hline $\mathrm{HDL}(\mathrm{mg} / \mathrm{dl})$ & $65.97 \pm 11.58$ & $42.43 \pm 24.40$ & $4.753 \bullet$ & 0.001 \\
\hline $\mathrm{LDL}$ (mg/dl) & $86.70 \pm 18.86$ & $93.60 \pm 54.41$ & $0.656 \bullet$ & 0.514 \\
\hline Triglycerides (mg/dl) & $70.13 \pm 39.13$ & $131.40 \pm 88.10$ & $-3.481 \bullet$ & 0.001 \\
\hline
\end{tabular}

\#: Mann Whitney test.

Table 3. Comparison between control group and patients group regarding cTn-I level.

\begin{tabular}{ccccc}
\hline & $\begin{array}{c}\text { Control group } \\
\text { NO. 30 }\end{array}$ & $\begin{array}{c}\text { Patients group } \\
\text { NO. 30 }\end{array}$ & test value p-value \\
\cline { 2 - 4 } & Mean \pm SD & Mean \pm SD & & \\
\hline Pre-dialysis & $0.189 \pm 0.005$ & $0.250 \pm 0.069$ & 4.904 & 0.000 \\
Post-dialysis & $0.189 \pm 0.005$ & $0.187 \pm 0.004$ & -1.693 & 0.090 \\
Difference & -- & $-0.063 \pm 0.069$ & - & - \\
Willcoxon & -- & 4.967 & & \\
Rank test & -- & 0.001 & & \\
P-value & & & & \\
\hline
\end{tabular}


Table 4. Cardiac symptoms and ECG abnormalities in patients group.

\begin{tabular}{|c|c|c|}
\hline \multicolumn{2}{|c|}{ ECG abnormalities } & $\begin{array}{c}\text { Patients group } \\
\text { No. }=30\end{array}$ \\
\hline Cardiac symptoms & No & $30(100.0 \%)$ \\
\hline Abnormal p-wave & No & $30(100.0 \%)$ \\
\hline Prolonged P-R & No & $30(100.0 \%)$ \\
\hline \multirow{2}{*}{ Prolonged QT interva } & No & $14(46.7 \%)$ \\
\hline & Prolonged & $16(53.3 \%)$ \\
\hline \multirow{2}{*}{ Prolonged QTC } & No & $20(66.7 \%)$ \\
\hline & Prolonged & $10(33.3 \%)$ \\
\hline \multirow[b]{2}{*}{ Prolonged QTC } & No & $20(66.7 \%)$ \\
\hline & Prolonged & $10(33.3 \%)$ \\
\hline \multirow{2}{*}{ Inverted $\mathrm{T}$ wave } & No & $23(76.7 \%)$ \\
\hline & Inverted & $7(23.3 \%)$ \\
\hline RA enlargement & No & $30(100.0 \%)$ \\
\hline RV enlargement & No & $30(100.0 \%)$ \\
\hline LA enlargement & No & $30(100.0 \%)$ \\
\hline \multirow{2}{*}{ LV enlargement } & No & $24(80.0 \%)$ \\
\hline & Enlarged & $6(20.0 \%)$ \\
\hline
\end{tabular}

Table 5 shows a significant positive correlation between troponin with systolic and diastolic blood pressure, heart rate, serum urea, creatinine, phosphate, ferritin, PTH, prolonged QT and QTC, but there is a significant negative correlation with $\mathrm{Hb}, \mathrm{Htc} \%$, and $\mathrm{HDL}$ serum level.

Figure 1, Figure 2 demonstrate the percentage of cases with elevated hs-cTnI pre and post hemodialysis (73.3\%) and (3.3\%), respectively.

Table 6 and Figure 3 show that the specificity and sensitivity of hs-cTnI in early detection of early myocardial injury pre HD is $96.67 \%$ and $90.1 \%$, respectively.

\section{Discussion}

Established high prevalence of cardiovascular mortality in patients on hemodialysis without current or ongoing cardiac events. Troponin ( $\mathrm{Tn}$ ) is a component of a heart muscle, and its release indicates early events in heart tissue degeneration, necrosis, and myocyte damage [16]. Cardiac troponins (cTnI) are sensitive markers of myocardial injury and play an essential role in diagnosing cardiac ischemia [17]. There is scarce data on the significance of cTnI levels in hemodialysis patients [18]. No studies were using hsTnI assay in HD children, and almost all were in the adult population. 
Table 5. Correlation between hsTnI and the study parameters.

\begin{tabular}{|c|c|c|}
\hline \multirow{2}{*}{ Variable } & \multicolumn{2}{|c|}{ hs-cTnI (ng/ml) } \\
\hline & $\mathbf{r}$ & p-value \\
\hline SBP (mmHg) & $0.333^{* *}$ & 0.009 \\
\hline DBP (mmHg) & $0.343^{* *}$ & 0.007 \\
\hline HR (beat/min) & $0.276^{\star}$ & 0.033 \\
\hline $\operatorname{TLC}\left(\times 10^{3} / \mu \mathrm{l}\right)$ & 0.106 & 0.421 \\
\hline $\operatorname{RBCs}\left(\times 10^{6} / \mu \mathrm{l}\right)$ & $-0.300^{*}$ & 0.020 \\
\hline $\mathrm{Hb}(\mathrm{g} / \mathrm{dl})$ & $-0.333^{\star *}$ & 0.009 \\
\hline Hct (\%) & 0.047 & 0.723 \\
\hline PLT $\left(\times 10^{3} / \mu \mathrm{l}\right)$ & $-0.375^{\star *}$ & 0.003 \\
\hline $\mathrm{MCV}(\mathrm{FL})$ & -0.117 & 0.375 \\
\hline Urea (mg/dl) & $0.592^{\star *}$ & 0.000 \\
\hline $\mathrm{Cr}(\mathrm{mg} / \mathrm{dl})$ & $0.494^{* *}$ & 0.000 \\
\hline $\mathrm{Ca}(\mathrm{mg} / \mathrm{dl})$ & -0.147 & 0.262 \\
\hline $\mathrm{Ph}(\mathrm{mg} / \mathrm{dl})$ & $0.525^{\star *}$ & 0.000 \\
\hline PTH (Pg/ml) & $0.532^{\star *}$ & 0.000 \\
\hline Ferritin $(\mu \mathrm{g} / \mathrm{L})$ & $0.534^{\star *}$ & 0.000 \\
\hline HDL (mg/dl) & $-0.324^{*}$ & 0.011 \\
\hline $\mathrm{LDL}(\mathrm{mg} / \mathrm{dl})$ & -0.124 & 0.345 \\
\hline Triglycerides (mg/dl) & 0.237 & 0.068 \\
\hline QT interval & $0.488^{* *}$ & 0.000 \\
\hline QTC & $0.368^{\star *}$ & 0.004 \\
\hline
\end{tabular}

Table 6. Sensitivity and specificity of hs-cTnI an early marker of myocardial injury in children on hemodialysis

\begin{tabular}{ccccccc}
\hline Variable & AUC & Cut of Point & Sensitivity & Specificity & PPV & NPV \\
\hline hsTnI $(\mathrm{ng} / \mathrm{ml})$ & 0.944 & $>0.197$ & 90.00 & 96.67 & 96.4 & 90.6 \\
\hline
\end{tabular}

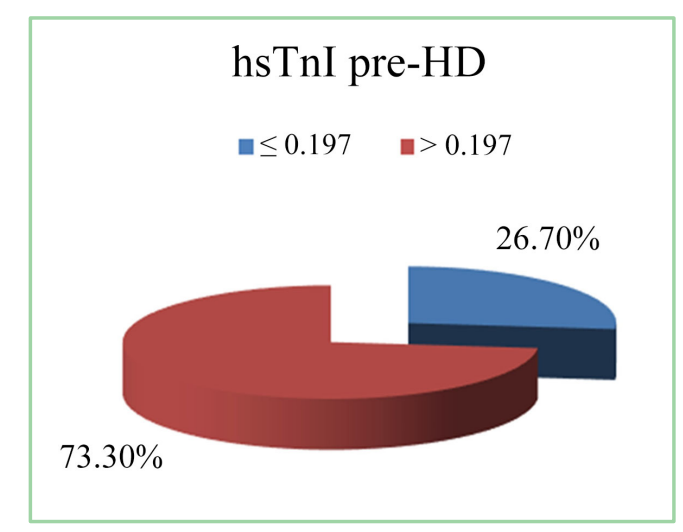

Figure 1. Percentage of patients with high level of hs-cTnI pre-HD. 


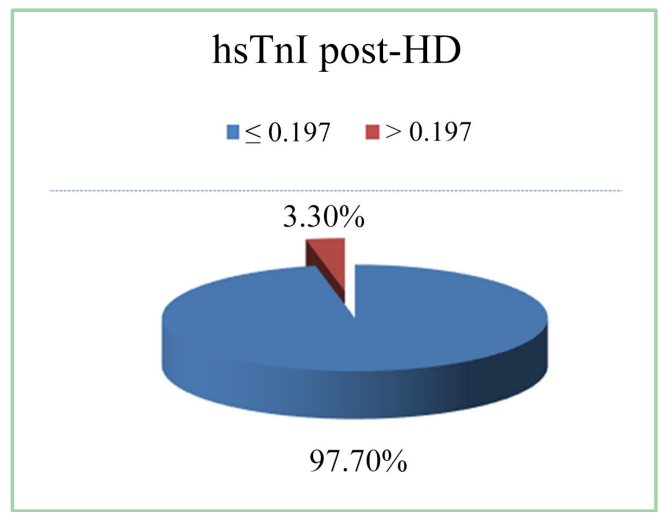

Figure 2. Percentage of patients with high level of hs-cTnI post-HD.

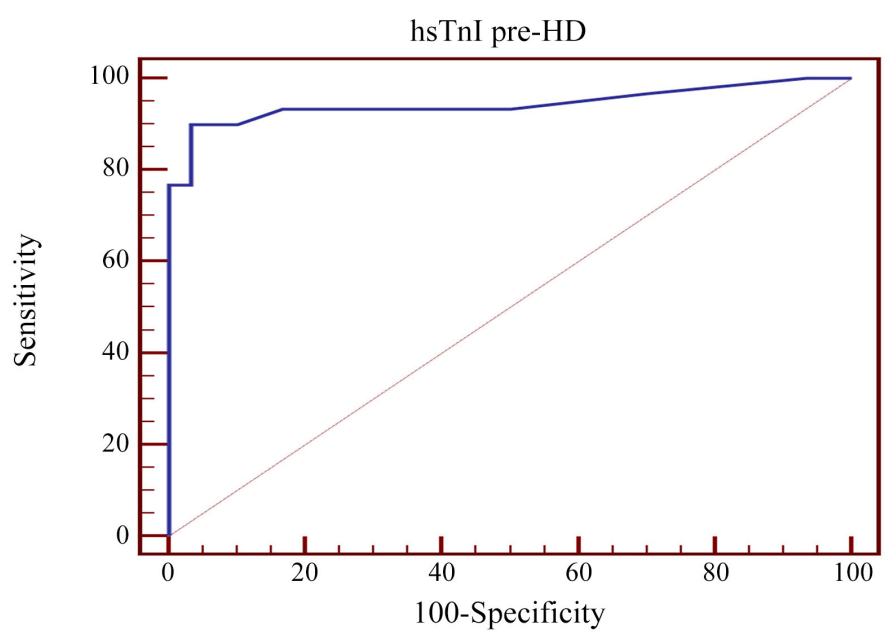

Figure 3. ROC curve demonstrates sensitivity and specificity of serum hsTnI as a marker of early myocardial injury pre-HD.

In the current study (cTnI) measured by sensitive assay pre-HD and repeated after hemodialysis in children without cardiac symptoms, we found a significantly high (cTnI) pre-HD. Cardiac troponin-I values are generally not elevated in children with stable cardiac disease or general pediatric conditions [19].

Asymptomatic children with higher pre-dialysis hsTnI levels than the reference cutoff point was (73.30\%); troponin is challenging to detect in unaffected muscle, but troponin levels rise several hours after the onset of myocardial injury [16], and fortunately, troponin level returned to baseline after the hemodialysis session except (3.3\%) of the study cases, the suggested cut off point hsTnI was derived from the controls included in the current study, previous studies Gaiki et al. (2012) [20], Artunc et al. (2012) [21], Assa et al. (2013) [22], Cardinaels et al. (2015) [13], and Skadberg et al. (2016) [23] were reported similar findings but in the adult population; also Tarapan et al. (2019) [24] reported the percentage of asymptomatic HD patients study who had higher pre-dialysis hsTnI levels than the reference cutoff point were $73 \%$.

Elevated troponin concentrations in dialysis patients possible causes are both 
cardiac and non-cardiac, such as left ventricular systolic dysfunction, left ventricular hypertrophy, volume overload, and decreased clearance [21] [25] [26] [27] [28]; we found that a more extraordinary rise of cTnI pre-dialysis was significantly associated hypertension, anemia, elevated urea, and creatinine. Some cross-sectional studies on clinically stable HD patients have found hscTnI is strongly correlated to left ventricular dysfunction and hs-cTnT to coronary artery disease based on a single troponin value [29]. Other conditions that may lead to troponin release are subclinical ischemic heart disease, anemia, arrhythmias, hypertension, angina [30], physical exertion [31], myocardial stunning [32], and intradialytic hypotension [33]. Troponin is released during myocardial damage and due to the loss of myocyte contraction force. After starting onset of irreversible cardiomyocyte damage occurred a similar release of intact cTnI and cTnT and their degradation products due to cardiomyocytes' metabolic inhibition [34] [35]. Increased troponin levels serve as a sensitive and specific biomarker of myocardial injury during the early stages and refer to the beginning of a micro infarct [36]. However, no morphological finding was reported showing the damage in the echocardiography [37]. We recorded in the present work cTnT emerges as a sensitive and specific fore detection of silent myocardial injury in hemodialysis children.

Their study on the association between anemia and $\mathrm{T}$ troponin reported a relationship between increased troponin and inadequate erythropoiesis and decreased hemoglobin and considered it a reflection of cardio-myopathy injury [38].

Some studies reported no overall change in troponin level, Tun et al. (1998) [39], Farkouh et al. (2003) [40], and Deleaval et al. (2006) [41], whereas other studies Wayand et al. (2000) [42], and Lippi et al. (2008) [43], found a decrease in cTnI levels during hemodialysis. These studies were all performed using conventional cTnI assays. Assa et al. (2013) [22] found that cTnI levels rose during hemodialysis in the majority (66\%) of patients.

Growth failure and protein-energy wasting may be related to higher troponin levels; we observed it in the current study patients group and typical for the uraemic phenotype [44]. Elevated troponin could be explained because PEW is related to fluid overload in dialysis patients [45]. The dry weight towards which a patient's dialysis prescription is complex and falsely determined in PEW's presence leads to chronic fluid overload, myocardial stretch, and troponin release.

In the current study, the HDL fraction and triglyceride are significantly elevated in hemodialysis children, and HDL fraction had an inverse relationship with hs-cTnI. This result is consistent with de Goma et al. (2001) [46], where an inverse relationship between HDL cholesterol and the prevalence of coronary heart disease (CHD) was observed. This relationship is probably due to HDL's role in transporting cholesterol from peripheral tissue to the liver for its subsequent catabolism and excretion Nayak et al. (2010) [47].

In our study, the patients' electrocardiography was also recorded and inter- 
preted by the cardiologists in the current study. We observed prolonged QT and QTC of ECG patterns, and this pattern is associated with high troponin levels in hemodialysis children. The prevalence of acquired long QT syndrome is high and increases with kidney function decline in CKD patients [48]-[55]. Also, the risk of QTc prolongation and the inverted $\mathrm{T}$ wave is higher in a hemodialysis patient. Hemodialysis patients had a series of poor conditions, such as volume overload, metabolism disorder, and uremic toxin accumulation, which lead to asymptomatic myocardial damage [56], which strengthens the current study finding also Ozdemir et al. (2005) [57] had reported greater QTc interval compared to control subjects and concluded that children receiving hemodialysis might be at greater risk of ventricular arrhythmia and sudden death. In contradiction to Valsangiacomo et al. (2007) [58], conducted on nine children, no changes in the QTc related to hemodialysis. This discrepancy may reflect the smaller number of cases included in their work.

Also, increased QT interval and dispersal on an electrocardiogram (ECG) are associated with LVH; and is detected in $6(20.0 \%)$ of the current study cases; LVH is an adaptive response to chronic pressure and volume overload (allowing maintenance of systolic function) and is the most common cardiovascular abnormality in children with CKD, Nashwa et al. (2009) [59]. Beaubien et al. (2002) [60] reported similar findings.

The current study showed a significant relationship between hs-cTnI and ferritin; there is no previous study recorded this finding in hemodialysis children, but Shahramian et al. (2013) [61] reported in micro infarct, troponin increases independent of ferritin, but this finding in patients with thalassemia and iron overload without cardiac symptoms. Also, Wood (2011) [62] studied the impact of iron assessment by MRI and stated that an increase of ferritin would increase the risk of cardiac toxicity.

In the present work, there is a significant association between hs-cTnI with phosphate and PTH serum level; the hypothesis shows the deleterious effect of high phosphate and PTH on the cardiovascular system and is reflected in the current investigations by elevated hsTnI. Van Ballegooijen et al. (2013) [63] reported a significant similar association between PTH receptors have been demonstrated in the heart and exert a trophic effect on cardiomyocytes; furthermore, PTH activates protein kinase $\mathrm{C}$, which could lead to hypertrophic growth and expression of fetal type proteins in cardiomyocytes [64]. Moreover, it might contribute to biochemical changes and an increase in LV mass and incident heart failure [65] [66] [67].

In the current study, significant low platelets count in hemodialysis children, aggregation of platelets during dialysis may be due to exposure of blood to the roller pump segment of the dialysis tubing or microbubbles. Heparin used in hemodialysis may also contribute to HD-associated platelet activation and thrombocytopenia [68] [69]. Platelets secrete and express many crucial mediators of coagulation, inflammation, thrombosis, and atherosclerosis [70] [71]. A significant association of blood platelet counts and troponin was detected; these find- 
ings raise the hypothesis of platelets' potential importance in the underlying pathophysiology of cardiovascular disease.

In conclusion, children on regular hemodialysis might have silent myocardial ischemia detected by hs-cTnI before hemodialysis with multifactorial etiologies; the nephrology team should aggressively treat those patients to prevent further myocardial damage, and hsTnI emerges as a highly sensitive and specific marker for early diagnosis of early myocardial damage in hemodialysis children.

\section{Conflicts of Interest}

The authors declare no conflicts of interest regarding the publication of this paper.

\section{References}

[1] Litwin, M., Grenda, R., Prokurat, S., Abuauba, M., Latoszyñska, J., Jobs, K., Boguszewska-Baczkowska, A. and Wawer, Z.T. (2001) Patient Survival and Causes of Death on Hemodialysis and Peritoneal Dialysis-Single-Center Study. Pediatric Nephrology, 16, 996-1001. https://doi.org/10.1007/s004670100012

[2] Groothoff, J.W., Gruppen, M.P., Offringa, M., Hutten, J., Lilien, M.R., Van De Kar, N.J., Wolff, E.D., Davin, J.C. and Heymans, H.S. (2002) Mortality and Causes of Death of End-Stage Renal Disease in Children: A Dutch Cohort Study. Kidney International, 61, 621-629. https://doi.org/10.1046/j.1523-1755.2002.00156.x

[3] Rinat, C., Becker-Cohen, R., Nir, A., Feinstein, S., Shemesh, D., Algur, N., Ben Shalom, E., Farber, B. and Frishberg, Y. (2010) A Comprehensive Study of Cardiovascular Risk Factors, Cardiac Function and Vascular Disease in Children with Chronic Renal Failure. Nephrology Dialysis Transplantation, 25, 785-793. https://doi.org/10.1093/ndt/gfp570

[4] Parekh, R.S., Carroll, C.E., Wolfe, R.A. and Port, F.K. (2002) Cardiovascular Mortality in Children and Young Adults with End-Stage Kidney Disease. The Journal of Pediatrics, 141, 191-197. https://doi.org/10.1067/mpd.2002.125910

[5] Chavers, B.M., Molony, J.T., Solid, C.A., Rheault, M.N. and Collins, A.J. (2015) One-Year Mortality Rates in US Children with End-Stage Renal Disease. American Journal of Nephrology, 41, 121-128. https://doi.org/10.1159/000380828

[6] Kari, J.A., Donald, A.E., Vallance, D.T., Bruckdorfer, K.R., Leone, A., Mullen, M.J., Bunce, T., Dorado, B., Deanfield, J.E. and Rees, L. (1997) Physiology and Biochemistry of Endothelial Function in Children with Chronic Renal Failure. Kidney International, 52, 468-472. https://doi.org/10.1038/ki.1997.354

[7] Shroff, R.C., Donald, A.E., Hiorns, M.P., Watson, A., Feather, S., Milford, D., Ellins, E.A., Storry, C., Ridout, D., Deanfield, J. and Rees, L. (2007) Mineral Metabolism and Vascular Damage in Children on Dialysis. Journal of the American Society of Nephrology, 18, 2996-3003. https://doi.org/10.1681/ASN.2006121397

[8] Hothi, D.K., Harvey, E., Goia, C.M. and Geary, D. (2008) Blood-Volume Monitoring in Paediatric Haemodialysis. Pediatric Nephrology, 23, 813-820. https://doi.org/10.1007/s00467-007-0724-7

[9] Prkacin, I., Jurekovic, Ž., Perkov, S., Savuk, A., Pikivaca, T., Golub, A. and Svagusa, T. (2018) High Sensitive Troponin Concentration Stability in Dialysate of Anuric Patients on Hemodialysis. Signa Vitae: Journal for Intensive Care and Emergency Medicine, 14, 35-38. 
[10] Yildiz, G., Kayataş, M., Candan, F., Yilmaz, M.B., Zorlu, A. and Sarikaya, S. (2013) What Is the Meaning of Increased Myocardial Injury Enzymes during Hemodialysis? A Tissue Doppler Imaging Study. Cardiorenal Medicine, 3, 136-153. https://doi.org/10.1159/000353154

[11] Ingec, M., Oguz, E.G., Yildirim, T., Ulas, T. and Horoz, M. (2014) The Effect of Hemodialysis on Cardiac Enzyme Levels and Echocardiographic Parameters. The International Journal of Artificial Organs, 37, 513-520.

https://doi.org/10.5301/ijao.5000333

[12] Kumar, N., Michelis, M.F., DeVita, M.V., Panagopoulos, G. and Rosenstock, J.L. (2011) Troponin I Levels in Asymptomatic Patients on Haemodialysis Using a High-Sensitivity Assay. Nephrology Dialysis Transplantation, 26, 665-670. https://doi.org/10.1093/ndt/gfq442

[13] Cardinaels, E.P., Cornelis, T., van der Sande, F.M., Leunissen, K.M., van Dieijen-Visser, M.P., Mingels, A.M., Kooman, J.P. and Bekers, O. (2015) Acute Effects of Conventional and Extended Hemodialysis and Hemodiafiltration on High-Sensitivity Cardiac Troponins. Clinical Chemistry and Laboratory Medicine (CCLM), 53, e289-e292. https://doi.org/10.1515/cclm-2015-0201

[14] Pervan, P., Svagusa, T., Perkov, S. and Prkacin, I. (2017) Troponina I u urinu. Acta Medica Croatica. (In Press)

[15] Locatelli, F., Nissenson, A.R., Barrett, B.J., Walker, R.G., Wheeler, D.C., Eckardt, K.U., Lameire, N.H. and Eknoyan, G. (2008) Clinical Practice Guidelines for Anemia in Chronic Kidney Disease: Problems and Solutions. A Position Statement from Kidney Disease: Improving Global Outcomes (KDIGO). Kidney International, 74, 1237-1240. https://doi.org/10.1038/ki.2008.299

[16] Zoltani, C.K. (2014) Cardiovascular Toxicity Biomarkers. In: Biomarkers in Toxicology, Elsevier, Amsterdam, 199-215. https://doi.org/10.1016/B978-0-12-404630-6.00011-7

[17] Thygesen, K., Alpert, J.S., White, H.D. and Joint ESC/ACCF/AHA/WHF Task Force for the Redefinition of Myocardial Infarction (2007) Universal Definition of Myocardial Infarction. Journal of the American College of Cardiology, 50, 2173-2195. https://doi.org/10.1016/j.jacc.2007.09.011

[18] Beciani, M., Tedesco, A., Violante, A., Cipriani, S., Azzarito, M., Sturniolo, A. and Splendiani, G. (2003) Cardiac Troponin I (2nd Generation Assay) in Chronic Haemodialysis Patients: Prevalence and Prognostic Value. Nephrology Dialysis Transplantation, 18, 942-946. https://doi.org/10.1093/ndt/gfg057

[19] Hirsch, R., Landt, Y., Porter, S., Canter, C.E., Jaffe, A.S., Ladenson, J.H., Grant, J.W. and Landt, M. (1997) Cardiac Troponin I in Pediatrics: Normal Values and Potential Use in the Assessment of Cardiac Injury. The Journal of Pediatrics, 130, 872-877. https://doi.org/10.1016/S0022-3476(97)70271-3

[20] Gaiki, M.R., DeVita, M.V., Michelis, M.F., Panagopoulos, G. and Rosenstock, J.L. (2012) Troponin I as a Prognostic Marker of Cardiac Events in Asymptomatic Hemodialysis Patients Using a Sensitive Troponin I Assay. International Urology and Nephrology, 44, 1841-1845. https://doi.org/10.1007/s11255-012-0128-x

[21] Artunc, F., Mueller, C., Breidthardt, T., Twerenbold, R., Peter, A., Thamer, C. Weyrich, P., Haering, H.U. and Friedrich, B. (2012) Sensitive Troponins-Which Suits Better for Hemodialysis Patients? Associated Factors and Prediction of Mortality. https://doi.org/10.1371/journal.pone.0047610

[22] Assa, S., Gansevoort, R.T., Westerhuis, R., Kobold, A.C.M., Voors, A.A., de Jong, P.E., Bakker, S.J. and Franssen, C.F. (2013) Determinants and Prognostic Signific- 
ance of an Intra-Dialysis Rise of Cardiac Troponin I Measured by Sensitive Assay in Hemodialysis Patients. Clinical Research in Cardiology, 102, 439-445.

https://doi.org/10.1007/s00392-013-0551-8

[23] Skadberg, Ø., Sandberg, S., Røraas, T., Petersen, P.H., Sellevoll, H., Svarstad, E., Sæle, K. and Aakre, K.M. (2016) The Variation in High Sensitive Cardiac Troponin Concentration during Haemodialysis Treatment Is Not Similar to the Biological Variation Observed in Stable end Stage Renal Disease Patients. Scandinavian Journal of Clinical and Laboratory Investigation, 76, 645-652.

https://doi.org/10.1080/00365513.2016.1230886

[24] Tarapan, T., Musikatavorn, K., Phairatwet, P., Takkavatakarn, K., Susantitaphong, P., Eiam-Ong, S. and Tiranathanagul, K. (2019) High Sensitivity Troponin-I Levels in Asymptomatic Hemodialysis Patients. Renal Failure, 41, 393-400.

https://doi.org/10.1080/0886022X.2019.1603110

[25] Antlanger, M., Hecking, M., Haidinger, M., Werzowa, J., Kovarik, J.J., Paul, G., Eigner, M., Bonderman, D., Hörl, W.H. and Säemann, M.D. (2013) Fluid Overload in Hemodialysis Patients: A Cross-Sectional Study to Determine Its Association with Cardiac Biomarkers and Nutritional Status. BMC Nephrology, 14, 266.

https://doi.org/10.1186/1471-2369-14-266

[26] Breidthardt, T., Burton, J.O., Odudu, A., Eldehni, M.T., Jefferies, H.J. and McIntyre, C.W. (2012) Troponin T for the Detection of Dialysis-Induced Myocardial Stunning in Hemodialysis Patients. Clinical Journal of the American Society of Nephrology, 7, 1285-1292. https://doi.org/10.2215/CJN.00460112

[27] Diris, J.H., Hackeng, C.M., Kooman, J.P., Pinto, Y.M., Hermens, W.T. and van Dieijen-Visser, M.P. (2004) Impaired Renal Clearance Explains Elevated Troponin T Fragments in Hemodialysis Patients. Circulation, 109, 23-25.

https://doi.org/10.1161/01.CIR.0000109483.45211.8F

[28] Fahim, M.A., Hayen, A.D., Horvath, A.R., Dimeski, G., Coburn, A., Tan, K.S., Johnson, D.W., Craig, J.C., Campbell, S.B. and Hawley, C.M. (2015) Biological Variation of High Sensitivity Cardiac Troponin-T in Stable Dialysis Patients: Implications for Clinical Practice. Clinical Chemistry and Laboratory Medicine (CCLM), 53, 715-722. https://doi.org/10.1515/cclm-2014-0838

[29] Buiten, M.S., de Bie, M.K., Rotmans, J.I., Dekker, F.W., van Buren, M., Rabelink, T.J., Cobbaert, C.M., Schalij, M.J., van der Laarse, A. and Jukema, J.W. (2015) Serum Cardiac Troponin-I Is Superior to Troponin-T as a Marker for Left Ventricular Dysfunction in Clinically Stable Patients with End-Stage Renal Disease. PLoS ONE, 10, e0134245. https://doi.org/10.1371/journal.pone.0134245

[30] Wildi, K., Twerenbold, R. and Mueller, C. (2015) How Acute Changes in Cardiac Troponin Concentrations Help to Handle the Challenges Posed by Troponin Elevations in Non-ACS-Patients. Clinical Biochemistry, 48, 218-222.

https://doi.org/10.1016/j.clinbiochem.2014.09.003

[31] Agewall, S. and Tjora, S. (2011) Physical Exertion May Cause High Troponin Levels. Tidsskr Nor Laegeforen, 131, 2226. https://doi.org/10.4045/tidsskr.11.0815

[32] Burton, J.O., Jefferies, H.J., Selby, N.M. and McIntyre, C.W. (2009) Hemodialysis-Induced Cardiac Injury: Determinants and Associated Outcomes. Clinical Journal of the American Society of Nephrology, 4, 914-920.

https://doi.org/10.2215/CJN.03900808

[33] Hung, S.Y., Hung, Y.M., Fang, H.C., Yeh, J.H., Hung, G.C., Wu, C.J., Chou, K.J. and Chung, H.M. (2004) Cardiac Troponin I and Creatine Kinase Isoenzyme MB in Patients with Intradialytic Hypotension. Blood Purification, 22, 338-343.

https://doi.org/10.1159/000079188 
[34] Thygesen, K., Alpert, J.S. and White, H.D. (2007) Universal Definition of Myocardial Infarction. European Heart Journal, 28, 2525-2538.

[35] Hessel, M.H., Michielsen, E.C., Atsma, D.E., Schalij, M.J., van der Valk, E.J., Bax, W.H., et al. (2008) Release Kinetics of Intact and Degraded Troponin I and T after Irreversible Cell Damage. Experimental and Molecular Pathology, 85, 90-95. https://doi.org/10.1016/j.yexmp.2008.07.002

[36] Kaplan, S. (1997) Biochemical Markers of Myocardial Injury in Children. Circulation, 96, 2496-2497.

[37] Noori, N.M., Keshavarz, K. and Shahriar, M. (2012) Cardiac and Pulmonary Dysfunction in Asymptomatic Beta-Thalassanemia Major. Asian Cardiovascular and Thoracic Annals, 20, 555-559. https://doi.org/10.1177/0218492312439706

[38] Adams Jr., K.F., Mehra, M.R., Oren, R.M., O’Connor, C.M., Chiong, J.R., Ghali, J.K., et al. (2010) Prospective Evaluation of the Association between Cardiac Troponin $\mathrm{T}$ and Markers of Disturbed Erythropoiesis in Patients with Heart Failure. American Heart Journal, 160, 1142-1148. https://doi.org/10.1016/j.ahj.2010.07.033

[39] Tun, A., Khan, I.A., Win, M.T., Hussain, A., Hla, T.A., Wattanasuwan, N., et al. (1998) Specificity of Cardiac Troponin I and Creatine Kinase-MB Isoenzyme in Asymptomatic Long-Term Hemodialysis Patients and Effect of Hemodialysis on These Cardiac Markers. Cardiology, 90, 280-285. https://doi.org/10.1159/000006859

[40] Farkouh, M.E., Robbins, M.J., Zafar, M.U., Shimbo, D., Davidson, K.W., Puttappa, R., et al. (2003) Association between Troponin I Levels and Mortality in Stable Hemodialysis Patients. The American Journal of Medicine, 114, 224-226. https://doi.org/10.1016/S0002-9343(02)01482-1

[41] Deleaval, P., Descombes, E., Magnin, J.L., Martin, P.Y. and Fellay, G. (2006) Differences in Cardiac Troponin I and T Levels Measured in Asymptomatic Hemodialysis Patients with Last Generation Immunoassays. Néphrologie \& Thérapeutique, 2, 75-81.

[42] Wayand, D., Baum, H., Schatzle, G., Scharf, J. and Neumeier, D. (2000) Cardiac Troponin T and I in End-Stage Renal Failure. Clinical Chemistry, 46, 1345-1350. https://doi.org/10.1093/clinchem/46.9.1345

[43] Lippi, G., Tessitore, N., Montagnana, M., Salvagno, G.L., Lupo, A. and Guidi, G.C. (2008) Influence of Sampling Time and Ultrafiltration Coefficient of the Dialysis Membrane on Cardiac Troponin I and T. Archives of Pathology \& Laboratory Medicine, 132, 72-76. https://doi.org/10.5858/2008-132-72-IOSTAU

[44] Fouque, D., Kalantar-Zadeh, K., Kopple, J., Cano, N., Chauveau, P., Cuppari, L., Franch, H., et al. (2008) A Proposed Nomenclature and Diagnostic Criteria for Protein-Energy Wasting in Acute and Chronic Kidney Disease. Kidney International, 73, 391-398. https://doi.org/10.1038/sj.ki.5002585

[45] Sur, M.M. and México, D.F. (2010) Body Fluid Volume and Nutritional Status in Hemodialysis: Vector Bioelectric Impedance Analysis. Clinical Nephrology, 73, 300-308.

[46] Degoma, E.M., Leeper, N.J. and Heidenreich, P.A. (2008) Clinical Significance of High-Density Lipoprotein Cholesterol in Patients with Low Low-Density Lipoprotein Cholesterol. Journal of the American College of Cardiology, 51, 49-55. https://doi.org/10.1016/j.jacc.2007.07.086

[47] Nayak, S.B., Pinto Pereira, L.M., Boodoo, S., KimberlyAli, A., Baptiste, C., Maraj, S., Persad, N., Khan, N., Surendran, S. and Legall, G. (2010) Association of Troponin T and Altered Lipid Profile in Patients Admitted with Acute Myocardial Infarction. Archives of Physiology and Biochemistry, 116, 21-27. https://doi.org/10.3109/13813450903397638 
[48] Patanè, S., Marte, F., Di Bella, G., Currò, A. and Coglitore, S. (2008) QT Interval Prolongation, Torsade de Pointes and Renal Disease. International Journal of Cardiology, 130, e71-e73. https://doi.org/10.1016/j.ijcard.2007.11.070

[49] Familoni, O.B., Alebiosu, C.O. and Ayodele, O.E. (2006) Effects and Outcome of Haemodialysis on QT Intervals and QT Dispersion in Patients with Chronic Kidney Disease: Cardiovascular Topics. Cardiovascular Journal of South Africa, 17, 19-23.

[50] Sherif, K.A., Abo-Salem, E., Panikkath, R., Nusrat, M. and Tuncel, M. (2014) Cardiac Repolarization Abnormalities among Patients with Various Stages of Chronic Kidney Disease. Clinical Cardiology, 37, 417-421. https://doi.org/10.1002/clc.22277

[51] Näppi, S.E., Virtanen, V.K., Saha, H.H., Mustonen, J.T. and Pasternack, A.I. (2000) QTc Dispersion Increases during Hemodialysis with Low-Calcium Dialysate. Kidney International, 57, 2117-2122. https://doi.org/10.1046/j.1523-1755.2000.00062.x

[52] Niaki, M.R.K., Saravi, M., Oliaee, F., Akbari, R., Noorkhomami, S., Rad, S.H.B., Fallahpoor, K. and Ramezani, M.S. (2013) Changes in QT Interval before and after Hemodialysis. Caspian Journal of Internal Medicine, 4, 590.

[53] Oktavia, D., Nasution, S.A. and Setiati, S. (2013) The Clinical Factors' Prediction of Increased Intradialytic qt Dispersion on the Electrocardiograms of Chronic Hemodialysis Patients. Saudi Journal of Kidney Diseases and Transplantation, 24, 274. https://doi.org/10.4103/1319-2442.109571

[54] Genovesi, S., Rossi, E., Nava, M., Riva, H., De Franceschi, S., Fabbrini, P., et al. (2013) A Case Series of Chronic Haemodialysis Patients: Mortality, Sudden Death, and QT Interval. Europace, 15, 1025-1033. https://doi.org/10.1093/europace/eus412

[55] Liu, P., Han, D., Sun, X., Tan, H., Wang, Z., Liu, C., et al. (2019) Prevalence and Risk Factors of Acquired Long QT Syndrome in Hospitalized Patients with Chronic Kidney Disease. Journal of Investigative Medicine, 67, 289-294.

https://doi.org/10.1136/jim-2018-000798

[56] Littmann, L. (1999) Large T Wave Inversion and QT Prolongation Associated with Pulmonary Edema: A Report of Nine Cases. Journal of the American College of Cardiology, 34, 1106-1110. https://doi.org/10.1016/S0735-1097(99)00311-3

[57] Ozdemir, D., Mese, T., Agin, H., Calkavur, S. and Bak, M. (2005) Impact of Haemodialysis on QTc Dispersion in Children. Nephrology, 10, 119-123.

https://doi.org/10.1111/j.1440-1797.2005.00378.x

[58] Valsangiacomo, E., Neuhaus, T.J., Goetschel, P. and Bauersfeld, U. (2002) Cardiac Rhythm Disturbances in Children on Hemodialysis. Pediatric Nephrology, 17, 837-841. https://doi.org/10.1007/s00467-002-0976-1

[59] Adiele, D.K., Okafor, H.U., Ojinnaka, N.C., Onwubere, B.J., Odetunde, O.I. and Uwaezuoke, S.N. (2014) Echocardiographic Findings in Children with Chronic Kidney Disease as Seen in the Resource-Limited Setting. Néphrologie \& Thérapeutique, 4, 2161-0959. https://doi.org/10.4172/2161-0959.1000158

[60] Beaubien, E.R., Pylypchuk, G.B., Akhtar, J. and Biem, H.J. (2002) Value of Corrected QT Interval Dispersion in Identifying Patients Initiating Dialysis at Increased Risk of Total and Cardiovascular Mortality. American Journal of Kidney Diseases, 39, 834-842. https://doi.org/10.1053/ajkd.2002.32005

[61] Shahramian, I., Razzaghian, M., Ramazani, A.A., Ahmadi, G.A., Noori, N.M. and Rezaee, A.R. (2013) The Correlation between Troponin and Ferritin Serum Levels in the Patients with Major Beta-Thalassemia. International Cardiovascular Research Journal, 7, 51 .

[62] Wood, J.C. (2011) Impact of Iron Assessment by MRI. Hematology, No. 1, 443-450. https://doi.org/10.1182/asheducation-2011.1.443 
[63] van Ballegooijen, A.J., Visser, M., Kestenbaum, B., Siscovick, D.S., de Boer, I.H., Gottdiener, J.S., et al. (2013) Relation of Vitamin D and Parathyroid Hormone to Cardiac Biomarkers and to Left Ventricular Mass (from the Cardiovascular Health Study). The American Journal of Cardiology, 111, 418-424.

https://doi.org/10.1016/j.amjcard.2012.10.021

[64] Tastan, I., Schreckenberg, R., Mufti, S., Abdallah, Y., Piper, H.M. and Schlüter, K.D. (2009) Parathyroid Hormone Improves Contractile Performance of Adult Rat Ventricular Cardiomyocytes at Low Concentrations in a Non-Acute Way. Cardiovascular Research, 82, 77-83. https://doi.org/10.1093/cvr/cvp027

[65] Kestenbaum, B., Katz, R., de Boer, I., Hoofnagle, A., Sarnak, M.J. and Shlipak, M.G. (2011) Vitamin D, Parathyroid Hormone, and Cardiovascular Events among Older Adults. Journal of the American College of Cardiology, 58, 1433-1441. https://doi.org/10.1016/j.jacc.2011.03.069

[66] Saleh, F.N., Schirmer, H., Sundsfjord, J. and Jorde, R. (2003) Parathyroid Hormone and Left Ventricular Hypertrophy. European Heart Journal, 24, 2054-2060. https://doi.org/10.1016/j.ehj.2003.09.010

[67] Hagström, E., Ingelsson, E., Sundström, J., Hellman, P., Larsson, T.E., Berglund, L., et al. (2010) Plasma Parathyroid Hormone and Risk of Congestive Heart Failure in the Community. European Journal of Heart Failure, 12, 1186-1192.

https://doi.org/10.1093/eurjhf/hfq134

[68] Matsuo, T. and Wanaka, K. (2011) Heparin-Induced Thrombocytopenia and Hemodialysis. Journal of Blood Disorders and Transfusion, 2, 002. https://doi.org/10.4172/2155-9864.S2-002

[69] Daugirdas, J.T. and Bernardo, A.A. (2012) Hemodialysis Effect on Platelet Count and Function and Hemodialysis-Associated Thrombocytopenia. Kidney International, 82, 147-157. https://doi.org/10.1038/ki.2012.130

[70] Davì, G. and Patrono, C. (2007) Platelet Activation and Atherothrombosis. New England Journal of Medicine, 357, 2482-2494. https://doi.org/10.1056/NEJMra071014

[71] Coppinger, J.A., Cagney, G., Toomey, S., Kislinger, T., Belton, O., McRedmond, J.P., et al. (2004) Characterization of the Proteins Released from Activated Platelets Leads to Localization of Novel Platelet Proteins in Human Atherosclerotic Lesions. Blood, 103, 2096-2104. https://doi.org/10.1182/blood-2003-08-2804 